https://doi.org/10.46344/JBINO.2021.v10i02.34

\title{
CORRECTION OF LIPID PROFILE BY HERB
}

\author{
M Ismail Khoso, Shah Murad, Quratulain Saleem, Saleemullah Abro, Tarique Ahmed Maka, Wajid Abro \& \\ Seema Shah Murad
}

Consultant Physician at CMH Mangla, Pakistan

Prof/HOD, PHARMACOLOGY at IMDC/DANTH, Islamabad Pakistan

AP at Community Medicine Department, Karachi Medical Dental College (KMDC), Karachi, Pakistan

Assistant Professor of Physiology, Baqai Medical University, Karachi Pakistan

ENT Specialist at CMH Mangla, Pakistan

, Research Scholar at Microbiology at BMSI, JPMC Karachi Pakistan

Research Associate at NMC Karachi Pakistan

Shahhmurad65@gmail.com,

Today, doctors think about risk in broader terms. They evaluate HDL cholesterol levels in context, along with other risk factors. People with high blood triglycerides usually also have lower levels of the good kind of cholesterol, or HDL. Genetic factors, type 2 diabetes, smoking, being overweight and being sedentary can all lower HDL cholesterol. Women tend to have higher levels of HDL cholesterol than men do. LDL (bad) cholesterol: Since LDL is the bad kind of cholesterol, a low LDL level is considered good for your heart health. In the past, doctors relied on specific ranges for LDL. Today, doctors consider LDL levels as one factor among many when evaluating cardiovascular risk. Hyperlipidemia and Atherogenesis leading to development of coronary artery disease is one of the potent reason for mortality all over the world. In more than 500 research studies it has been proved that low HDLcholesterol is one of the etiological factor for development of atherogenesis. Since long green tea have had been used for raising HDL-cholesterol in ayurvedic medicine. We conducted the study on ethnic grounds that how much green tea can raise HDL-cholesterol in our Pakistani citizens. Sample size: Forty hyperlipidemic patients were selected from Ghurki Trust Teaching Hospital Lahore and divided in two groups with 20 patients in each group. Material \& Method: Group-I was advised to take, six hourly $180 \mathrm{ml}$ green tea prepared by conventional method for two months. Group-ll was labeled as control, not to take green tea for 2 months. Their HDL-cholesterol was measured at day-0 and on day-60. HDL-cholesterol was measured by separating other lipoprotein fractions using chemical precipitation with divalent ions such as $\mathrm{Mg}^{2+}$, then coupling the products of a cholesterol oxidase reaction to 
an indicator reaction. Results: After two months, it was observed that green tea consumption raised HDL-cholesterol $7.5 \mathrm{mg} / \mathrm{dl}$, while control group's HDL-cholesterol raised $0.8 \mathrm{mg} / \mathrm{dl}$ in this period. Statistical Analysis: Mean values with SD and SEM were analyzed statistically by using SPSS version 22.0.0.0. Statistical significant was considered according to p-value of changed parameter from day-0 to day-60. P-value of $<0.001$ was considered as significant and $p$-value of $>0.05$ was considered as non-significant change. Conclusion: After the research study it was concluded that green tea can raise HDL-cholesterol significantly and can be considered as negative risk factor for development of coronary artery disease.

\section{INTRODUCTION}

Low-density lipoprotein (LDL) is often called "bad cholesterol." It carries cholesterol to your arteries. If your levels of LDL cholesterol are too high, it can build up on the walls of your arteries. The buildup is also known as cholesterol plaque. This plaque can narrow your arteries, limit your blood flow, and raise your risk of blood clots. If a blood clot blocks an artery in your heart or brain, it can cause a heart attack or stroke. Atherogenesis can cause coronary artery disease leading to mortality due to heart attack and cardiac arrhythmias.1,3-8 Patients with coronary artery disease (CAD) commonly have low HDL cholesterol (HDL-C) and mildly elevated LDL cholesterol (LDL-C), leading to uncertainty as to whether the appropriate goal of therapy should be lowering LDL-C or raising HDL-C.6-8Many clinical studies suggest that $\mathrm{HDL}$ of $60 \mathrm{mg} / \mathrm{dl}$ is associated with dramatic reduction in rate of heart attack. Several studies suggest that higher levels of $\mathrm{HDL}$ are associated with less carotid and coronary atherosclerotic plaque. HDL particles are also protective against infections and even cancer, and are a major player in the body's fight against inflammatory patterns. In other words, HDL has clearly established itself as a blood particle that provides powerful protective functions.2,17-21 Tea, prepared from the leaves of Camella sinensis, is the most popular beverage in the world except water. Black tea, made from the mild oxidation of green tea leaves, amounts to $80 \%$ of world tea production. Flavonoids are a group of polyphenols present in vegetables, fruits and beverages such as tea and wine.11-12,16 Recent research studies shows that green tea lowers total cholesterol and raises HDL ("good") cholesterol in both animals and people. One population-based clinical study found that men who drink green tea are more likely to have lower total cholesterol than those who do not drink green tea. Results from one animal study suggest that polyphenols in green tea may block cholesterol from being absorbed in the intestine and also help the body get rid of cholesterol. In another small study of male smokers, researchers found that green tea significantly reduced blood levels of harmful LDL cholesterol.3-5 It's thought the antioxidants catechin and caffeine found in green tea may have a role in helping the body burn more calories - sometimes referred to as speeding up the metabolism - which can help weight loss. ${ }^{4-8}$ Green tea preparations used for losing weight are extracts of green tea that contain a higher concentration of catechins and caffeine than the typical green tea beverage prepared from a tea bag and boiling water. ${ }^{9}$ Eleven research studies involving 821 people found daily consumption of green and black tea (as a drink or a capsule) could help lower cholesterol and blood pressure 10 
High levels of LDL cholesterol are linked to atherosclerosis, which is the accumulation of cholesterol-rich fatty deposits in arteries ${ }^{13-5,21}$.

\section{MATERIAL \& METHOD}

Research study was conducted at Ghurki trust teaching hospital (GTTH), Lahore Pakistan from June 2018 to September 2018. Forty hyperlipidemic patients were selected from GTTH for the study. Age of patients ranged from 18 to 70 years. Both gender male and female patients were enrolled. They were advised to discontinue any hypolipidemic medications and foods. Patients suffering from any metabolic disease, renal impairment, liver disease, and already victimized by cardiac problems were excluded from the research study. Forty patients were divided in two groups, twenty individuals in each group. Group-1 was advised to take $180 \mathrm{ml}$ green tea boiled in hot water every six hourly for the period of eight weeks. Group-II was considered as control group and was advised not to take green tea, black tea or coffee for eight weeks. Their baseline values of $\mathrm{HDL}$-cholesterol were measured by separating other lipoprotein fractions using chemical precipitation with divalent ions such as $\mathrm{Mg}^{2+}$, then coupling the products of a cholesterol oxidase reaction to an indicator reaction. After two months, it was observed that green tea consumption by twenty hyperlipidemic patient's HDL-cholesterol was raised 7.5 $\mathrm{mg} / \mathrm{dl}$, while control group's HDLcholesterol raised $0.8 \mathrm{mg} / \mathrm{dl}$ in this period. Mean values with SD and SEM were analysed statistically by using SPSS version 22.0.0.0. Statistical significant was considered as $p$-value of changed parameter from day-0 to day-60. P-value of $<0.001$ was labeled as significant and $p$ value of $>0.05$ was considered as nonsignificant change.

\section{RESULTS}

After eight weeks of trial, following changes were observed in selected parameter of HDL-cholesterol. Results are self explanatory as showed in table 1.

Table 1 showing mean values before and after consumption of green tea with its $p$-value

\begin{tabular}{|l|l|l|l|l|l|}
\hline Group & Parameter & At D-0 & At D-60 & Change & $p$-value \\
\hline $\begin{array}{l}\text { Tested-Group-A } \\
(\mathrm{n}=20)\end{array}$ & LDL-C & $190.98 \pm 0.90$ & $170.87 \pm 1.98$ & $20.11 \mathrm{mg} / \mathrm{dl}$ & $<0.01$ \\
& HDL-C & $32.08 \pm 2.22$ & $39.54 \pm 1.96$ & $7.5 \mathrm{mg} / \mathrm{dl}$ & $<0.01$ \\
\hline $\begin{array}{l}\text { Placebo-Group- } \\
\text { B ( } \mathrm{n}=20)\end{array}$ & LDL-C & $171.23 \pm 2.01$ & $169.99 \pm 1.97$ & $1.24 \mathrm{mg} / \mathrm{dl}$ & $>0.05$ \\
& HDL-C & $35.10 \pm 2.03$ & $35.92 \pm 3.14$ & $0.8 \mathrm{mg} / \mathrm{dl}$ & $>0.05$ \\
\hline
\end{tabular}

KEY: Group-A is tested group, Group-B is placebo group. ' $n$ ' in groups indicates sample size, mean values are measured as mg/dl, HDL-C stands for high density lipoprotein cholesterol, \pm indicates SEM. P-value $<0.01$ indicates significant change and p-value $>0.05$ indicates non-significant change in parameter 


\section{DISCUSSION}

There are two types of cholesterol - blood or serum cholesterol, which naturally circulates in the bloodstream and comes from the liver and dietary cholesterol, which comes from food. Although the chemical substance of cholesterol is the same, it's transported in the blood using different carriers, referred to as LDL (LowDensity Lipoproteins), which is the "bad" cholesterol and HDL (High-Density Lipoproteins), which is the "good" cholesterol. High LDL cholesterol levels are harmful, while high levels of HDL are protective. Additionally, high LDL and total cholesterol blood levels are major risk factors for heart disease. Aim of research was to see LDL-c lowering effect and HDL$c$ raising effect of green tea in local population having risk of developing CAD. By two months consumption of green tea (180 ml/six hourly) it was proved that green tea increased $7.5 \mathrm{mg} / \mathrm{dl}$ of HDL-cholesterol, which is significant raise in the parameter. These results match with results of study conducted by Zhang $\mathrm{C}$ et al 22 who proved that green tea consumption for 5 weeks raised high density cholesterol from 39 $\mathrm{mg} / \mathrm{dl}$ to $45 \mathrm{mg} / \mathrm{dl}$ in 20 hyperlipidemic patients. Our results are in contrast with results of study conducted by Khan $\mathrm{N}$ and Mukhtar $\mathrm{H}^{23}$ who proved only $2.08 \mathrm{mg} / \mathrm{dl}$ raise in plasma HDL-cholesterol, when green tea was used by 17 hyperlipidemic patients for one month. This contrast may be due to less frequency of taking green tea by patients; ie 12 hourly. In our study control groups HDL-cholesterol was raised from $35.10 \pm 2.03 \mathrm{mg} / \mathrm{dl}$ to $35.92 \pm 3.14 \mathrm{mg} / \mathrm{dl}$ which is only $0.8 \mathrm{mg} / \mathrm{dl}$ increase in HDLcholesterol. This change is non-significant when analysed statistically. Arab $\mathrm{L}$ et $\mathrm{al}^{24}$ described that less consumption or no consumption of green tea does not mean that hyperlipidemic patients HDL cholesterol can not increase by other healthy habits like aerobic exercise and less frequency of taking junk food which contain lesser raw fat. Khalesi $S$ et $a^{25}$ explained that lesser the predisposing factors for coronary artery disease, lesser the risk for developing heart attack and cardiac arrhythmias in human beings. Our results match with results of study conducted by Johson $\mathrm{R}$ et $\mathrm{al}^{26}$ in which 10 $\mathrm{mg} / \mathrm{dl} \mathrm{HDL}$ cholesterol was increased in 39 hyperlipidemic patients when they took $200 \mathrm{ml}$ green tea every four hourly for the period of three months. They also mentioned hypoglycemic, and hypotensive effects of green tea consumption by primary hyperlipidemic patients suffering from metabolic syndrome. Not to smoke cigarettes, nonalcoholics and aerobic exercise can increase high density cholesterol in plasma. It is proved by cohort studies conducted by Peng $X$ et $a^{27}$ that old age, renal diseases, liver diseases, lesser lung function may contribute to lower high density lipoprotein cholesterol leading to development of atherogenesis, cardiac arrhythmias and cardiac arrest. Although eating some fat is necessary, eating too much of the wrong kinds of fats is not only unhealthy, it can lead to high cholesterol and increase the risk of heart disease and some forms of cancer. Even for those who eat a relatively healthy diet, maintain an exercise regimen or aren't obese, having a regular blood cholesterol test is essential to preventing the disease or taking the steps needed to bring unhealthy cholesterol levels down. Recognizing the risk factors for high cholesterol, as well understanding blood cholesterol levels allows patients and physicians to treat the condition before more serious health problems or diseases develop ${ }^{28-30}$.

CONFLICT OF INTEREST: N/A

FUNDING: N/A 


\section{REFERENCES}

1. LU X, Shi XT, Zheng JS, Yang J, FU YQ, Huang T, Huang YJ, Li D. "Effects of green tea, black tea, and coffee consumption on the risk of esophageal cancer: a systematic review and meta-analysis of observational studies". JMSC 2016;2(8):1015.

2. Huang $T H, F \cup Y Q$, Huang $Y Q$, LU $X, M i n ~ H$, WU QQ, Shi XT, Bian KQ, Zou XP. "Green tea and liver cancer risk: A meta-analysis of prospective cohort studies in Asian populations". NJMS 2017;17(7):34-7.

3. Min $H$, Zhung BV, Liu G, Mi XN, Zheng XX, $X \cup Y L$, LU J, Huang $X H$. "Effects of tea intake on blood pressure: a meta-analysis of randomised controlled trials". MSJ 2015;10(4):44-9.

4. Zheng $X X, X \cup Y L$, Li $S H$, Hui $R, W \cup Y J$, Huang XH. "Effects of green tea catechins with or without caffeine on glycemic control in adults: a meta-analysis of randomized controlled trials". Am J Clin Nutr (Meta-Analysis) 2013;97 (4): 750-62.

5. Liu K, Zhou R, Wang B, Chen K, Shi LY, Zhu JD, Mi MT. "Effect of green tea on glucose control and insulin sensitivity: a metaanalysis of 17 randomized controlled trials". Am J Clin Nutr (MetaAnalysis) 2013;98 (2): 340-8.

6. Nagao T, Hase T, Tokimitsu I. A green tea extract high in catechins reduces body fat and cardiovascular risks in humans. Obesity (Silver Spring). 2007;15(6):1473-83.

7. Tang J, Zheng JS, Fang L, Jin Y, Cai W, Li D. "Tea consumption and mortality of all cancers, CVD and all causes: a metaanalysis of eighteen prospective cohort studies". Br J Nutr (Meta-analysis): 2015;3:111.

8. Larsson SC. "Coffee, tea, and cocoa and risk of stroke". Stroke (Review) 2014;45 (1): 309-14.

9. Serban C, Sahebkar A, Antal D, Ursoniu S, Banach $M$. "Effects of supplementation with green tea catechins on plasma HDLcholesterol: A systematic review and metaanalysis of randomized controlled trials". Nutrition (Systematic review \& metaanalysis) 2015;31 (9): 1061-71.

10. Jurgens $T M$, Whelan $A M$, Killian $L$, Doucette S, Kirk S, Foy E. "Green tea for weight loss and weight maintenance in overweight or obese adults". Cochrane Database Syst Rev 2012; 12: 111-3.

11. Suzuki Y, Tsubono Y, Nakaya N, Suzuki Y, Koizumi Y, Tsuji I. Green tea and the risk of breast cancer: pooled analysis of two prospective studies in Japan. $\mathrm{Br} \mathrm{J}$ Cancer 2004;90(7)1361-1363.

12. Thatte U, Bagadey S, Dahanukar S. Modulation of programmed cell death by medicinal plants. Cell Mol Biol. 2000;46(1):199-214.

13. Thavanesan N. The putative effects of green tea on body fat: an evaluation of the evidence and a review of the potential mechanisms. Br J Nutr. 2011;3:1-13.

14. Trudel D, Labbe DP, Bairati I, Fradet V, Bazinet L, Tetu B. Green tea for ovarian cancer prevention and treatment: a systemic review of the in vitro, in vivo and 
epidemiological studies. Gynecol Oncol. 2012; 126(3):491-8.

15. Tsubono $Y$, Nishino $Y$, Komatsu $S$, et al. Green tea and the risk of gastric cancer in Japan.N Engl J Med. 2001;344(9):632-636.

16. Vinson JA, Teufel K, WU N. Green and black teas inhibit atherosclerosis by lipid, antioxidant, and fibrinolytic mechanisms. J Agric Food Chem. 2004;52(11):3661-5.

17. Wargovich MJ, Woods C, Hollis DM, Zander ME. Herbals, cancer prevention and health. J Nutr. 2001;131(11 Suppl):3034S-3036S.

18. Westerterp-Plantenga MS, Lejeune MP, Kovacs EM. Body weight and weight maintenance in relation to habitual caffeine intake and green tea. Obes Res 2005;13(7):1 195-1204.

19. Wu AH, Butler LM. Green tea and breast cancer. Mol Nutr Food Res. 2011;55(6):92130.

20. Yuan JM. Green tea and prevention of esophageal and lung cancers. Mol Nutr Food Res. 201 1;55(6):886-904.

21. Lambert JD, Sang S, Yang C."Possible controversy over dietary polyphenols",Chem Res

Toxicol 2007;20(4):583-5.

22. Zhang C, Qin YY, Wei X, YU FF, Zhou YH, $\mathrm{He} J$. "Tea consumption and raised HDL cholesterol. Eur J Epidemiology (Systematic Review and Meta-Analysis) 2015;30 (2): 103-13.

23. Khan N, Mukhtar H. "Tea and HDLcholesterol: studies in humans". Current pharmaceutical design 2013; 19 (34): 61417.

24. Arab L, Khan F, Lam H. "Tea consumption and cardiovascular disease risk". Am J Clin Nutr 2013;98 (6 Suppl): 1651S-1659S.

25. Khalesi S, Sun J, Buys N, Jamshidi A, Nikbakht-Nasrabadi E, Khosravi-Boroujeni $H$. "Green tea catechins and lipoprotein HDL: a systematic review and metaanalysis of randomised controlled trials". Eur J Nutr(Systematic Review and MetaAnalysis) 2014; 53 (6): 1299-1311.

26. Johnson R, Bryant S, Huntley AL. "Green tea and green tea catechin extracts: an overview of the clinical evidence on HDLcholesterol". Maturitas (Review) 2012;73 (4): 280-7.

27. Peng $X$, Zhou $R$, Wang $B, Y \cup X$, Yang $X$, Liu K, Mi M. "Effect of green tea consumption on blood pressure: a metaanalysis of 13 randomized controlled trials". Sci Rep 2014; 4: 6251.

28. Pezeng TY, Zheng XX, Xu YL, Li SH, Hui R, Wu YJ, Huang XH. "Effects of green tea catechins with or without caffeine on glycemic control in adults: a meta-analysis of randomized controlled trials". PSJR 2017;12(1):10-4

29. Rangy R, Liu K, Zhou R, Wang B, Chen K, Shi LY, Zhu JD, Mi MT. "Effect of green tea on glucose control and insulin sensitivity: a meta-analysis of 17 randomized controlled trials". UJMS 2016;17(8):90-6.

30. Chen K, Liu E, Liu G, Mi XN, Zheng XX, Xu $Y L$, LU J, Huang XH. "Effects of tea intake on blood pressure: a meta-analysis of 
randomised controlled trials". KJMS

2016;34(4):110-6

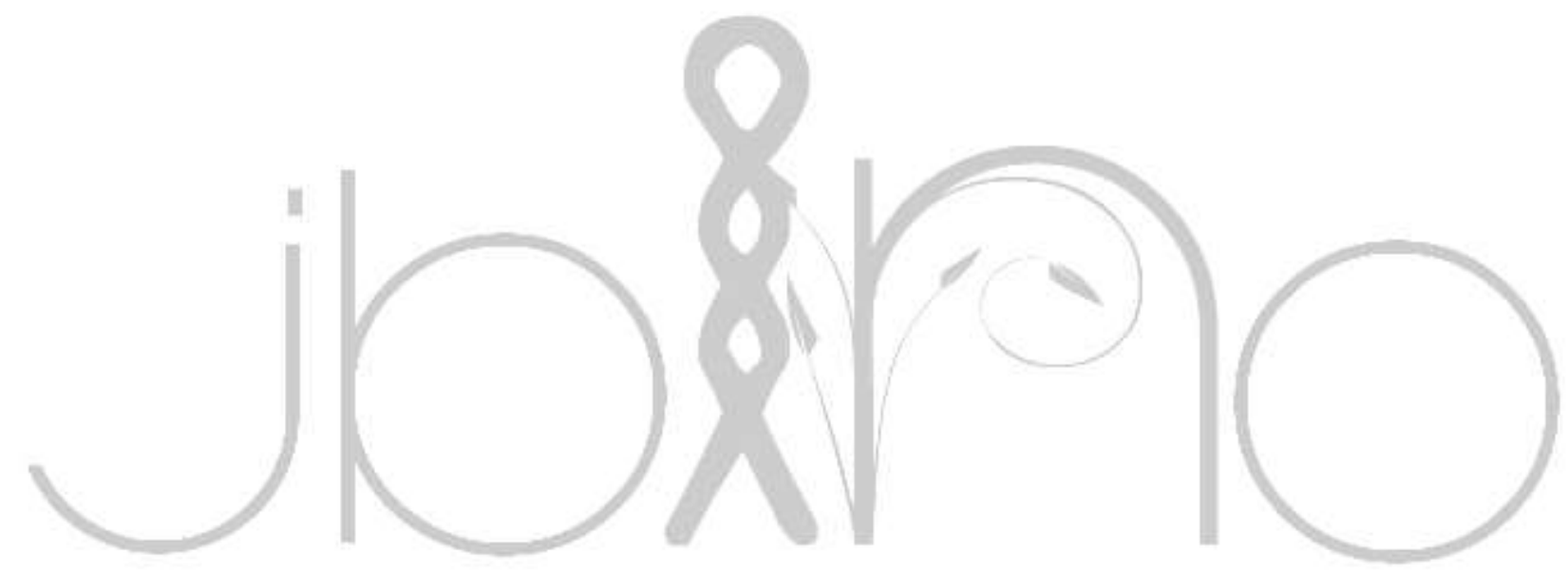

